\title{
An Elderly Patient with Sarcoidosis Manifesting Panhypopituitarism with Central Diabetes Insipidus
}

\author{
TOMOKO MIYOSHI, FUMIO OTSUKA, MASAYA TAKEDA, KENICHI INAGAKI, HIROYUKI OTANI, \\ TOSHIO OGURA, KEN ICHIKI*, TETSUKI AMANO* AND HIROFUMI MAKINO
}

Department of Medicine and Clinical Science, Okayama University Graduate School of Medicine, Dentistry and Pharmaceutical Sciences, 2-5-1 Shikata-cho, Okayama City, 700-8558, Japan

*Aioi City Hospital, 5-12 Sakae-cho, Aioi City, 678-0008, Japan

\begin{abstract}
We here report a 77-year-old Japanese male who suffered general fatigue with progressive thirst and polyuria. Central diabetes insipidus was diagnosed by depletion of vasopressin secretion in response to increases in serum osmolality. Secretory responses of anterior pituitary hormones including adrenocorticotropin, thyrotropin, gonadotropins and growth hormone were severely impaired. Diffuse swelling of the infundibulum as well as lack of T1-hyperintense signal in the posterior lobe was noted by pituitary magnetic resonance imaging. The presence of bilateral hilar lymphadenopathy and increased CD4/CD8 ratio in bronchoalveolar lavage fluid was diagnostic for lung sarcoidosis. Physiological doses of corticosteroid and thyroid hormone were administered in addition to desmopressin supplementation. Complete regression of the neurohypophysial swelling was notable two years after corticosteroid replacement. Diffuse damage of anterior pituitary combined with hypothalamic involvement leading to central diabetes insipidus is a rare manifestation in such elderly patients with neurosarcoidosis.
\end{abstract}

Key words: Central diabetes insipidus, Hypophysitis, Lymphocytic infundibuloneurohypophysitis, Neurosarcoidosis, Panhypopituitarism, Sarcoidosis

(Endocrine Journal 54: 425-430, 2007)

SARCOIDOSIS is a systemic granulomatous disease involving multiple organs, in which endocrinopathy is rarely complicated [1]. Among the various symptoms attributed to neuroendocrine sarcoidosis, polyuria and polydipsia are the most frequent manifestation, as reported in approximately $30 \%$ of patients with sarcoidosis involving the central nervous system [2-5]. However, considering that the central nervous system is affected only in $5 \%$ of all cases of sarcoidosis, diabetes insipidus resulting from sarcoidosis is still an uncommon complication [6, 7]. Patients with neuroendocrine sarcoidosis occasionally show hypothalamic

Received: September 13, 2006

Accepted: January 22, 2007

Corresponding to: Fumio OTSUKA, M.D., Ph.D., Department of Medicine and Clinical Science, Okayama University Graduate School of Medicine, Dentistry and Pharmaceutical Sciences, 2-5-1 Shikata-cho, Okayama City, 700-8558, Japan dysfunction and less frequently involve the infundibulum and/or the pituitary gland, leading to hypothalamic disturbances and anterior pituitary hormone deficiency [7].

Here we report an elderly patient with pulmonary sarcoidosis and central diabetes insipidus secondary to its hypothalamo-pituitary involvement, who was notable for loss of anterior pituitary functions and complete regression of the neurohypophysial enlargement after corticosteroid replacement.

\section{Case Presentation}

A 77-year-old Japanese male who suffered general fatigue, headache, thirst, polyuria, and polydipsia was referred to our hospital for further examination. He also had a low-grade fever. He presented a 4-month history of progressive thirst and had been ingesting 3 to 
$5 \mathrm{~L} /$ day of cold water. His daily urine volume was initially $2 \mathrm{~L}$ and gradually increased to 4 to $5 \mathrm{~L}$. He had no particular family history of endocrinopathy or sarcoidosis but had a previous history of hepatocellular carcinoma related to alcoholic liver damage. Laboratory screening excluded diabetes mellitus and renal insufficiency while it showed moderate anemia $(\mathrm{Hb}$ $11.1 \mathrm{~g} / \mathrm{dl}$ ), mild decrease of serum sodium level (133 $\mathrm{mEq} / \mathrm{l})$ and moderate liver damage. Corrected serum calcium level was normal $(9.3 \mathrm{mg} / \mathrm{dl})$ but 1,25 dihydroxyvitamin $\mathrm{D}_{3}$ level was slightly elevated (65 $\mathrm{pg} / \mathrm{ml}$, normal: 20-60). Levels of serum angiotensinconverting emzyme (ACE), lysozyme and soluble interleukin-2 receptor (sIL-2R) were 17.8 IU/1 (7-20), 11.7 $\mu \mathrm{g} / \mathrm{ml}$ (5-10), and $1250 \mathrm{U} / \mathrm{ml}$ (190-650), respectively. Chest X-ray (Fig. 1A) and computed tomography (CT; Fig. 1B) showed bilateral swelling of hilar lymph nodes and small nodules in bilateral lung fields. Arterial blood-gas analysis and pulmonary function tests were normal. Scintigraphy using ${ }^{67} \mathrm{Ga}$-citrate revealed diffuse uptake in bilateral lung fields. Lung sarcoidosis was diagnosed based on the specific findings of high CD4/CD8 ratio of 9.78 , in the bronchoalveolar lavage fluid (BALF) containing $31.2 \times 10^{6} / \mathrm{ml}$ cells with $37.9 \%$ of lymphocyte population. It is reported that $\mathrm{CD} 4 / \mathrm{CD} 8$ ratio of 3.5 or greater in BALF had high specificity for diagnosing lung sarcoidosis [8]. The patient had no neurological and ophthalmological abnormalities including visual field and the fundus. No lymphoadenopathy or skin nodules were detected by physical examination. Electrocardiogram and cardiac ultrasonography did not reveal findings related to cardiac sarcoidosis.

Basal endocrine data were as follows: arginine vasopressin (AVP): $0.3 \mathrm{pg} / \mathrm{ml}$ at $300 \mathrm{mOsm} / \mathrm{kg}$ of serum osmolality, adrenocorticotropin (ACTH): $1.5 \mathrm{pg} / \mathrm{ml}$, cortisol: $1.1 \mu \mathrm{g} / \mathrm{dl}$, luteinizing hormone (LH): 0.06 $\mathrm{mIU} / \mathrm{ml}$, follicle-stimulating hormone (FSH): 0.47 $\mathrm{mIU} / \mathrm{ml}$, thyrotropin (TSH): $0.3 \mu \mathrm{IU} / \mathrm{ml}$, free thyroxine (FT4): $0.68 \mathrm{ng} / \mathrm{dl}$, free triiodothyroxine (FT3): $1.54 \mathrm{pg} /$ $\mathrm{ml}$, prolactin (PRL): $18.7 \mathrm{ng} / \mathrm{ml}$, and growth hormone (GH): $0.29 \mathrm{ng} / \mathrm{ml}$. Posterior pituitary function test using 5\% saline loading test (Fig. 2A) revealed that secretion of AVP was markedly impaired. None of the anterior pituitary hormones except PRL responded to a combined test of anterior pituitary function with $\mathrm{CRH}$, GnRH, TRH and GRH (Fig. 2B). Anti-pituitary antibodies tested by immunofluorescence using rat pituitary anterior and middle lobes [9] were negative and

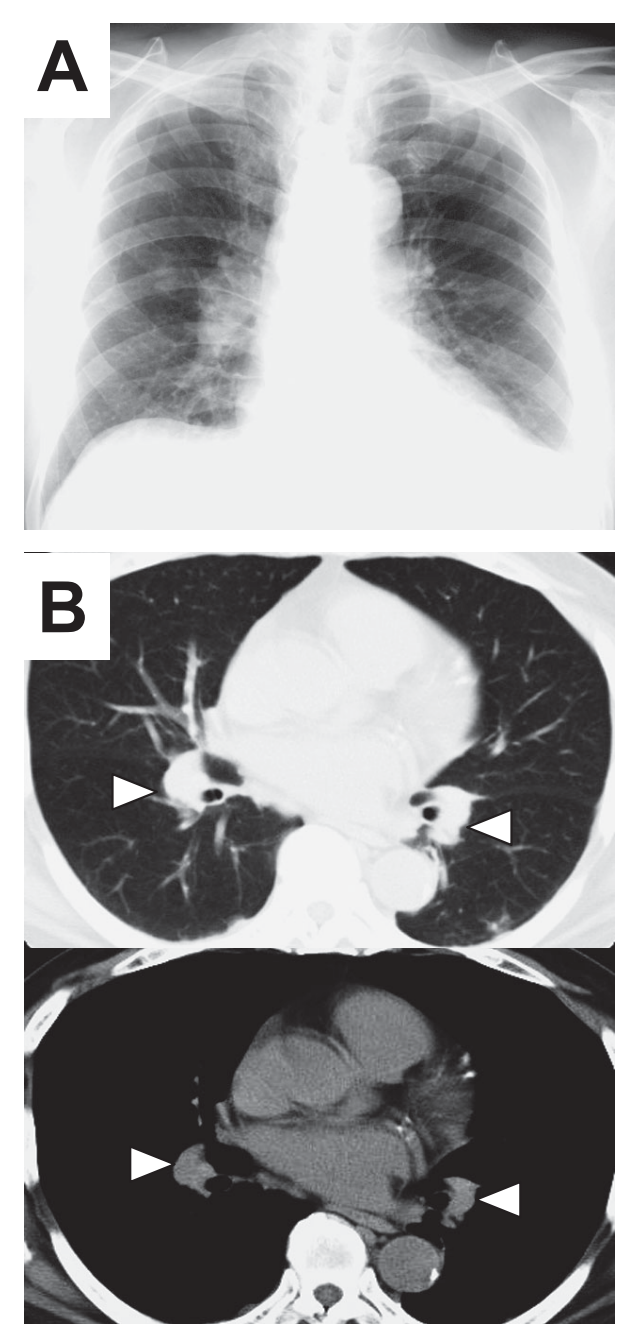

Fig. 1. Radiological findings in the lung. A) Chest X-ray and B) Computed tomography. Arrowheads indicate bilateral swelling of hilar lymphnodes.

anti-thyroglobulin and anti-thyroid peroxidase antibodies were not detected in the serum. Pituitary magnetic resonance imaging (MRI) enhanced with gadolinium contrast exhibited marked thickening of the infundibulum (Fig. 3A). In addition, normal hyperintense signal in the neurohypophysis was absent in T1-image and dural thickening was observed.

Treatment was initiated with hydrocortisone (10 to $25 \mathrm{mg}$ /day) for replacement of hypocortisolemia. Administration of levothyroxine sodium ( 25 to $75 \mu \mathrm{g}$ /day) was also required for concurrent hypothyroidism even after hydrocortisone replacement (Fig. 4). Immediately after the replacement of hydrocortisone, urinary volume was increased to $5 \mathrm{~L}$ /day possibly due to unmasked diabetes insipidus. Nasal administration of 

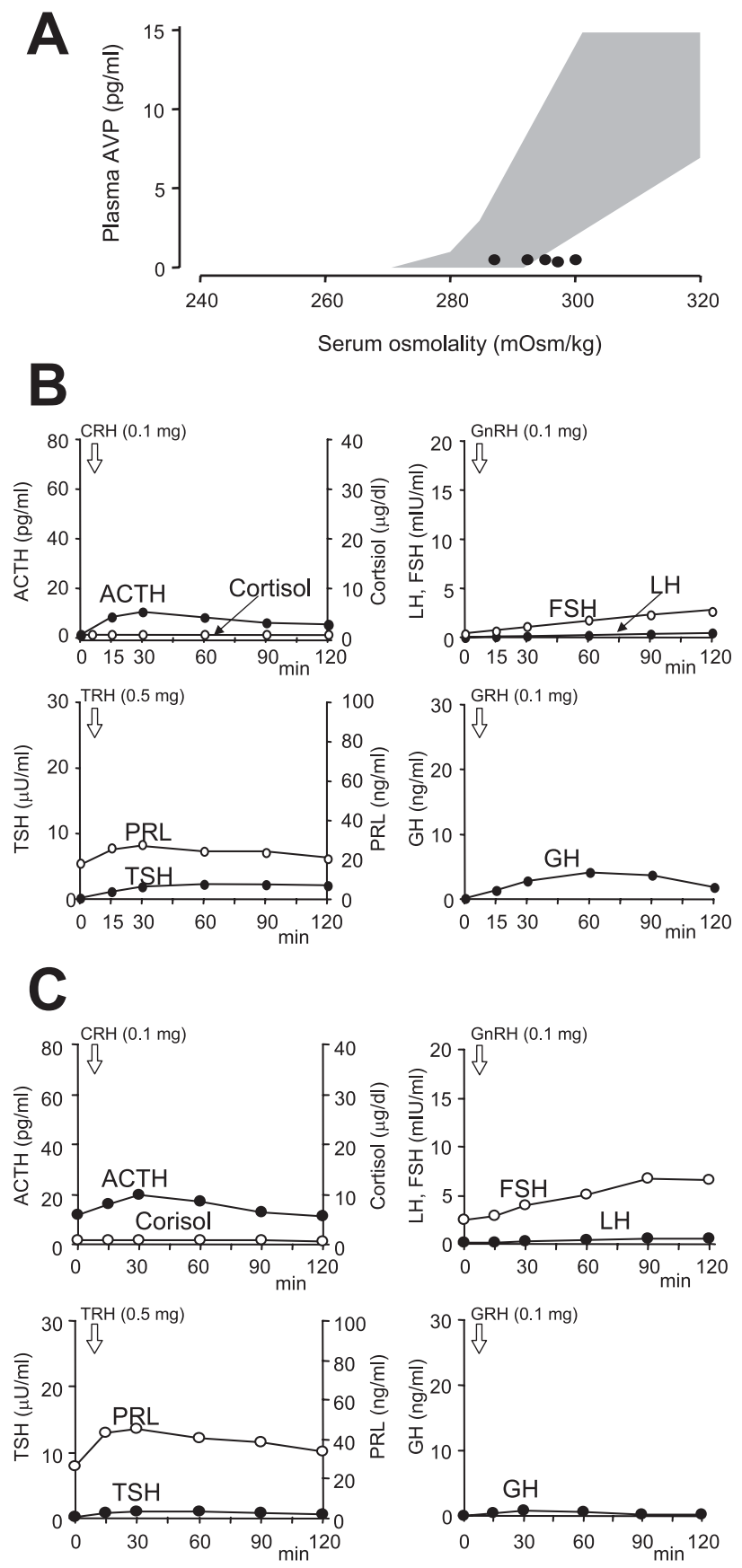

Fig. 2. Pituitary function tests. A) Posterior pituitary functions. AVP, arginine vasopressin. A shaded area indicates normal range (26). B, C) Combined anterior pituitary tests. Before (B) and after $(\mathrm{C})$ replacement of hydrocortisone for 2 years. CRH $(0.1 \mathrm{mg})$, GnRH $(0.1 \mathrm{mg})$, TRH $(0.5$ $\mathrm{mg})$ and GRH $(0.1 \mathrm{mg})$ were intravenously administered.

desmopressin (2.5 to $5 \mu \mathrm{g} /$ day) was then commenced (Fig. 4). A trial of initial administration of $2.5 \mu \mathrm{g}$ desmopressin resulted in marked reduction of urinary
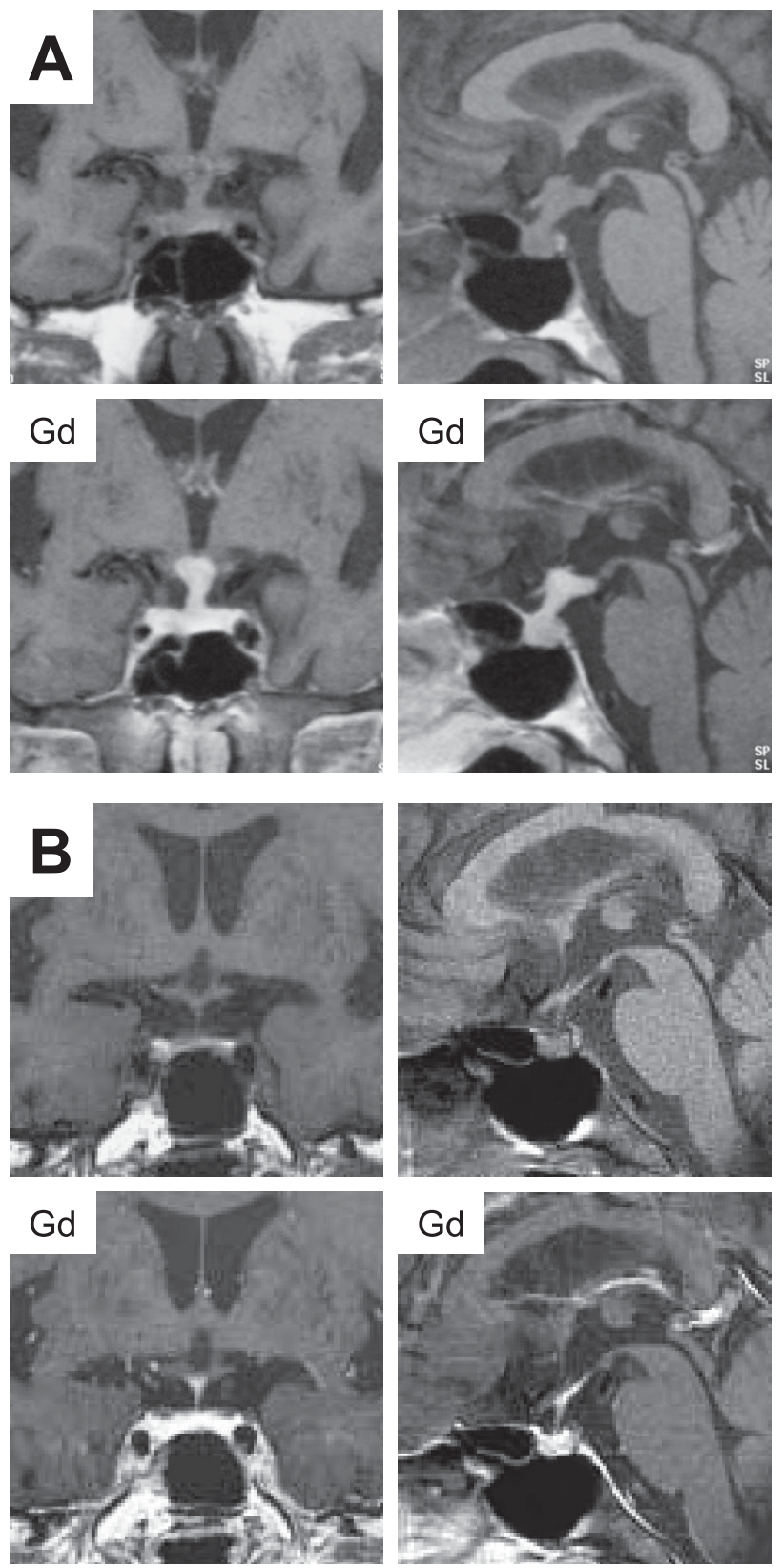

Fig. 3. Pituitary MRI findings. A) At the onset of diabetes insipidus. B) After replacement of hydrocortisone for 2 years. Gd: gadolinium enhancement.

volume from $200 \mathrm{ml} / \mathrm{h}$ to less than $50 \mathrm{ml} / \mathrm{h}$ in $2 \mathrm{~h}$, suggesting normal urine concentrating ability of the kidney. After commencement of two-year corticosteroid replacement, follow-up MRI showed a complete remission of the thickening of pituitary stalk, despite the absence of normal hyperintense signal of the neurohypophysis (Fig. 3B). The patient has recovered from his headache, lethargy and weight loss, but has contin- 


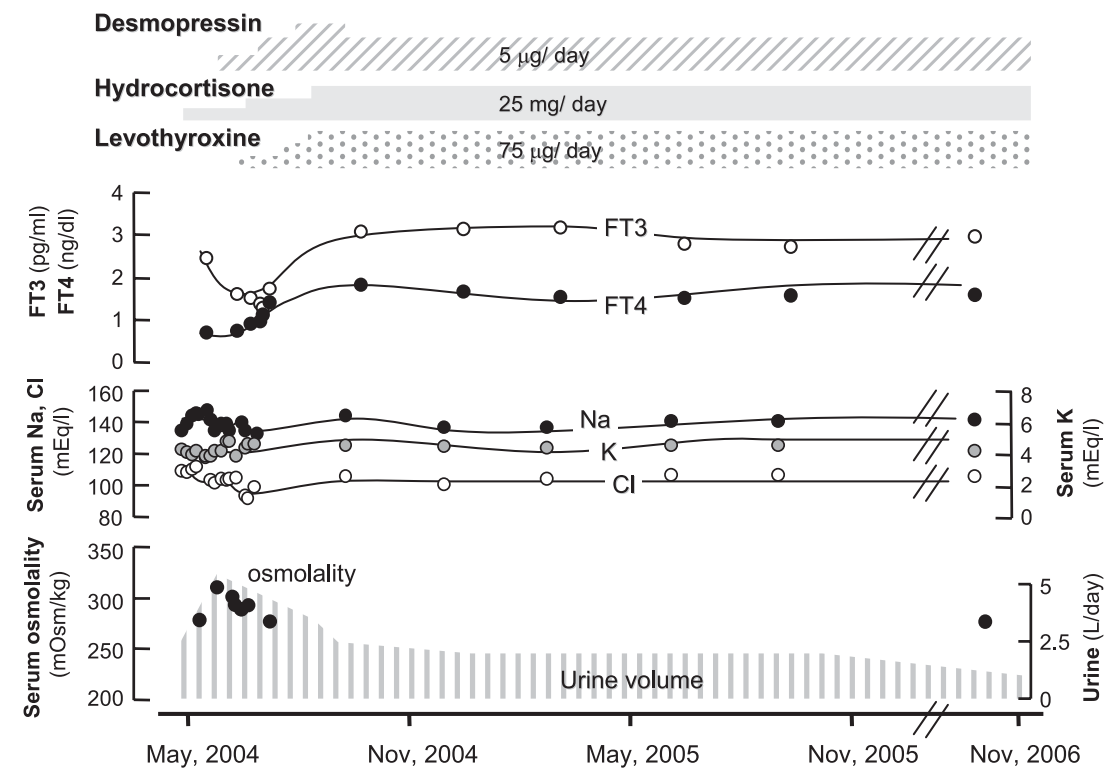

Fig. 4. Clinical course.

ued to require desmopressin treatment for diabetes insipidus. Examination of combined anterior pituitary test after two-year hydrocortisone replacement revealed that responses of ACTH, PRL and FSH were marginally increased (Fig. 2C). Serum levels of lysozyme, 1,25-dihydroxyvitamin $\mathrm{D}_{3}$ and sIL-2R decreased to $7.1 \mu \mathrm{g} / \mathrm{ml}, 18 \mathrm{pg} / \mathrm{ml}$ and $803 \mathrm{U} / \mathrm{ml}$, respectively.

\section{Discussion}

In this report we described an elderly patient who initially manifested with masked central diabetes insipidus and panhypopituitarism. Neuroendocrine damage of the anterior pituitary combined with central diabetes insipidus is a rare complication in elderly patients with sarcoidosis. Based on the review on 285 patients with sarcoidosis (mean age: 43.7 , male to female ratio 5/4) [6], mean age of 14 patients with neurosarcoidosis was 44 years old and female patients were predominant (male to female ratio 4/10). Murialdo and Tamagno have specifically reviewed 91 patients with neuroendocrine dysfunctions due to neurosarcoidosis, showing that the age of patients with endocrine manifestations related to hypothalamo-pituitary region ranged from 10 to 66 years (mean age: 33 years) without gender prominence [2].

Neurological complications of sarcoidosis include cranial neuropathy including facial, vestibular and oculomotor palsy, aseptic meningitis, myopathy, hydrocephalus, hypothalamo-pituitary involvement, and peripheral neuropathy [6]. Since the preceding neurological manifestations occur without any evidence of pulmonary or other systemic features of sarcoidosis, actual incidence and course of isolated neurosarcoidosis are still uncertain [6]. The occurrence of subclinical and undiagnosed neurosarcoidosis may be much higher. Although the hypothalamus and pituitary are the most susceptible endocrine organs in sarcoidosis, confined involvement in the pituitary gland is rare complication in sarcoidosis [10]. Although polyuria and polydipsia are common features of hypothalamic involvement of sarcoidosis, these symptoms may be partially caused by thirst dysregulation rather than true diabetes insipidus [11].

Serum levels of ACE and sIL-2R are useful parameters with high specificity and sensitivity for the detection and evaluation of systemic activity of sarcoidosis. ACE is produced in sarcoid granulomas by immigrated macrophages [12], while sIL-2R produced by Tlymphocytes reflects the specific T-cell response of the inflammation [13]. The sIL-2R level is known to have higher sensitivity (83\%) than the serum ACE level in pulmonary sarcoidosis and therefore it appears to be an indicator of disease progression [14]. In our case, serum levels of lysozyme and sIL-2R decreased when pituitary swelling had disappeared, suggesting that the disease activity of sarcoidosis regressed after cor- 
ticosteroid replacement for two years.

Regarding the manifestation of central diabetes insipidus, lymphocytic adenohypophysitis (LAH) and lymphocytic infundibuloneurohypophysitis (LIN) are important differential diagnoses from neurosarcoidosis [15]. LAH is a rare autoimmune disorder of the pituitary that most frequently observed in females during the postpartum period [16]. The symptoms include headache, visual disturbance and signs of anterior pituitary insufficiency. In contrast, the main lesion of LIN is localized at the pituitary stalk and/or posterior lobe. According to the review by Hashimoto concerning LIN [17], damage of GH and gonadotropin secretion was occasionally found, while ACTH secretion was rarely impaired ( 1 out of 28 LIN cases). On the other hand, impaired secretion of diffuse anterior hormones including ACTH, TSH, gonadotropins, GH and PRL was often observed in LAH patients [16]. Increased serum PRL was occasionally found in one third of patients with sarcoidosis, suggesting that the hypothalamus is more susceptible to sarcoidosis than the pituitary gland [18]. Considering the self-limiting feature of pituitary-stalk thickening observed in LIN, LIN could be overlapped in the present case with sarcoidosis. In addition, periventricular distribution of lesions and leptomeningeal enhancement are the two most common abnormal findings in neurosarcoidosis [19]. The latter finding observed in our case was helpful in discriminating neurosarcoidosis from multiple sclerosis and lymphocytic hypophysitis.

Complete regression of the neurohypophysial swelling was noted after corticosteroid replacement for two years although the defects of anterior pituitary responses such as ACTH, PRL and FSH were only marginally alleviated. The therapeutic effects of corticosteroids on hypothalamo-pituitary involvement due to sarcoidosis have been proposed [19]. In general, the effectiveness to restore anterior pituitary function and diabetes insipidus is unexpected [20], although a case of neurosarcoidosis showing complete resolution of the suprasellar mass as well as recovery of concurrent hypogonadism is documented [21]. Clinical courses of sarcoidosis are varied and advanced disease with extensive granulomatous involvement leads to irreversible neurological deficit [22]. It is therefore important to diagnosis neurosarcoidosis in the early phase [23]; however, necessity of corticosteroid therapy to sarcoidosis without showing significant neurological symptoms remains controversial.

In conclusion, we report a case of diabetes insipidus accompanying panhypopituitarism related to sarcoidosis. Swelling of the pituitary stalk regressed completely with corticosteroid replacement. Diffuse involvement of anterior pituitary combined with central diabetes insipidus is a rare condition but this complication should be clinically noted even in elderly patients with sarcoidosis. Sarcoidosis is associated with intrathoracic lesions in about $70 \%$ of cases [24] and normal chest Xray at initial presentation does not exclude generalized sarcoidosis [25]. Careful follow-up and an intensive search for systemic sarcoidosis are mandatory in patients with presumed involvement in the hypothalamopituitary region.

\section{References}

1. Porter N, Beynon HL, Randeva HS (2003) Endocrine and reproductive manifestations of sarcoidosis. Qjm 96: 553-561.

2. Murialdo G, Tamagno G (2002) Endocrine aspects of neurosarcoidosis. J Endocrinol Invest 25: 650-662.

3. Stuart CA, Neelon FA, Lebovitz HE (1978) Hypothalamic insufficiency: the cause of hypopituitarism in sarcoidosis. Ann Intern Med 88: 589-594.

4. Vesely DL, Maldonodo A, Levey GS (1977) Partial hypopituitarism and possible hypothalamic involvement in sarcoidosis: report of a case and review of the literature. Am J Med 62: 425-431.

5. Takano K (2004) Sarcoidosis of the hypothalamus and pituitary. Intern Med 43: 894-895.

6. Chen RC, McLeod JG (1989) Neurological complica- tions of sarcoidosis. Clin Exp Neurol 26: 99-112.

7. Stern BJ, Krumholz A, Johns C, Scott P, Nissim J (1985) Sarcoidosis and its neurological manifestations. Arch Neurol 42: 909-917.

8. Costabel U (1997) CD4/CD8 ratios in bronchoalveolar lavage fluid: of value for diagnosing sarcoidosis? Eur Respir J 10: 2699-2700.

9. Sugiura M, Hashimoto A, Shizawa M, Tsukada M, Maruyama S, Ishido T, Kasahara T, Hirata Y (1986) Heterogeneity of anterior pituitary cell antibodies detected in insulin-dependent diabetes mellitus and adrenocorticotropic hormone deficiency. Diabetes Res 3: 111-114.

10. Loh KC, Green A, Dillon WP Jr, Fitzgerald PA, Weidner N, Tyrrell JB (1997) Diabetes insipidus from 
sarcoidosis confined to the posterior pituitary. Eur $J$ Endocrinol 137: 514-519.

11. Stuart CA, Neelon FA, Lebovitz HE (1980) Disordered control of thirst in hypothalamic-pituitary sarcoidosis. N Engl J Med 303: 1078-1082.

12. Lieberman J (1975) Elevation of serum angiotensinconverting-enzyme (ACE) level in sarcoidosis. Am J Med 59: 365-372.

13. Lawrence EC, Brousseau KP, Berger MB, Kurman CC, Marcon L, Nelson DL (1988) Elevated concentrations of soluble interleukin-2 receptors in serum samples and bronchoalveolar lavage fluids in active sarcoidosis. Am Rev Respir Dis 137: 759-764.

14. Ziegenhagen MW, Benner UK, Zissel G, Zabel P, Schlaak M, Muller-Quernheim J (1997) Sarcoidosis: TNF-alpha release from alveolar macrophages and serum level of sIL-2R are prognostic markers. Am J Respir Crit Care Med 156: 1586-1592.

15. Bullmann C, Faust M, Hoffmann A, Heppner C, Jockenhovel F, Muller-Wieland D, Krone W (2000) Five cases with central diabetes insipidus and hypogonadism as first presentation of neurosarcoidosis. Eur J Endocrinol 142: 365-372.

16. Hashimoto K, Nanamiya W, Takao T (1999) Clinicopathology of autoimmune hypophysitis. Endocrinol Diabetol 9: 534-540 (In Japanese).

17. Hashimoto K (1999) Lymphocytic hypophysitis. Clin Endocrinol 47: 1001-1009 (In Japanese).

18. Bell NH (1991) Endocrine complications of sarcoido- sis. Endocrinol Metab Clin North Am 20: 645-654.

19. Sharma OP (1997) Neurosarcoidosis: a personal perspective based on the study of 37 patients. Chest 112 : 220-228.

20. Tabuena RP, Nagai S, Handa T, Shigematsu M, Hamada K, Ito I, Izumi T, Mishima M, Sharma OP (2004) Diabetes insipidus from neurosarcoidosis: long-term followup for more than eight years. Intern Med 43: 960-966.

21. Hidaka N, Takizawa H, Miyachi S, Hisatomi T, Kosuda T, Sato T (1987) A case of hypothalamic sarcoidosis with hypopituitarism and prolonged remission of hypogonadism. Am J Med Sci 294: 357-363.

22. Vinas FC, Rengachary S (2001) Diagnosis and management of neurosarcoidosis. J Clin Neurosci 8: 505513.

23. Agbogu BN, Stern BJ, Sewell C, Yang G (1995) Therapeutic considerations in patients with refractory neurosarcoidosis. Arch Neurol 52: 875-879.

24. Chapelon C, Ziza JM, Piette JC, Levy Y, Raguin G, Wechsler B, Bitker MO, Bletry O, Laplane D, Bousser MG, et al. (1990) Neurosarcoidosis: signs, course and treatment in 35 confirmed cases. Medicine (Baltimore) 69: $261-276$.

25. Oksanen V (1986) Neurosarcoidosis: clinical presentations and course in 50 patients. Acta Neurol Scand 73: 283-290.

26. Robertson GL, Aycinena P, Zerbe RL (1982) Neurogenic disorders of osmoregulation. Am J Med 72: 339 353. 